\title{
Effects of propofol in lipid-based emulsion and in microemulsion on the incidence of endothelial lesion in rabbits ${ }^{1}$
}

\author{
Cristian Durço Paço ${ }^{I}$, Matheus Fachini Vane ${ }^{I I}$, Rafael Bicarato de Andrade ${ }^{I I I}$, Maria Aparecida Domingues ${ }^{\text {IV }}$, Lidia Raquel de \\ Carvalhov, Daniela Carvalho dos Santos $^{\text {VI, Regina Kiomi Takahira }}{ }^{\mathrm{VII}}$, Norma Sueli Pinheiro Modolo ${ }^{\mathrm{VIII}}$, Luiz Antonio Vane ${ }^{\mathrm{IX}}$ \\ IFellow Master degree, Postgraduate Program in Anesthesiology, Botucatu Medical School, Sao Paulo State University (UNESP), Botucatu-SP, Brazil. \\ Conception, design and intellectual content of the study.

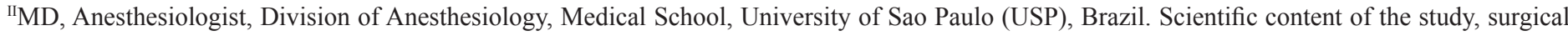 \\ procedures. \\ IIIGraduate student, Botucatu Medical School, UNESP, Botucatu-SP, Brazil. Surgical procedures. \\ ${ }^{\text {IV }} \mathrm{PhD}$, Assistant Professor, Department of Pathology, Botucatu Medical School, UNESP, Botucatu-SP, Brazil. Histological analysis. \\ ${ }^{\mathrm{V}} \mathrm{PhD}$, Assistant Professor, Department of Biostatistics, Biosciences of Institute, UNESP, Botucatu-SP, Brazil. Acquisition and interpretation of data. \\ ${ }^{\mathrm{V}} \mathrm{PhD}$, Assistant Professor, Department of Pathology, Biosciences Institute, UNESP, Botucatu-SP, Brazil. Histological analysis.

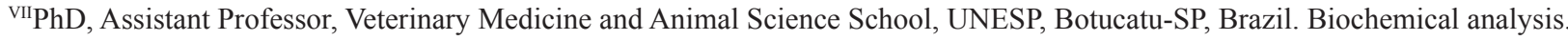 \\ VIIIPhD, Full Professor, Department of Anesthesiology, Botucatu Medical School, UNESP, Botucatu-SP, Brazil. Critical revision. \\ ${ }^{\mathrm{IX} P h D}$, Full Professor, Department of Anesthesiology, Botucatu Medical School, UNESP, Botucatu-SP, Brazil. Supervised all phases of the study, \\ manuscript writing.
}

\begin{abstract}
PURPOSE: To compare the incidence of endothelial injury after single-dose or continuous propofol infusion in conventional lipidbased emulsion (LE) versus microemulsion (ME).

METHODS: Forty-two rabbits (2.5-4.5 Kg) were randomly allocated into seven groups of six animals each: SHAM- surgical treatment alone; Bolus Control Group - 3 mL-intravenous (IV) bolus of saline; Continuous Infusion Control Group - $3 \mathrm{~mL}$ - IV bolus of saline followed by a continuous infusion of $0.2 \mathrm{ml} / \mathrm{kg} / \mathrm{min}$ for $60 \mathrm{~min}$; Bolus LE Propofol Group - IV bolus of LE propofol (3 mg/kg); Bolus ME Propofol Group - IV ME propofol bolus (3 mg/kg); Continuous LE Propofol Group - IV LE propofol bolus (3 mg/kg) followed by a continuous infusion of $0.2 \mathrm{ml} / \mathrm{kg} / \mathrm{min}$ for $60 \mathrm{~min}$; Continuous ME Propofol Group - IV ME propofol bolus (3 mg/kg) followed by a continuous infusion of $0.2 \mathrm{ml} / \mathrm{kg} / \mathrm{min}$ for $60 \mathrm{~min}$.

RESULTS: There were no statistically significant differences between the studied groups in blood pressure, in central venous pressure and in the biochemical profile. No significant differences were found in inflammatory mediators and in tissue analysis between the two emulsions.
\end{abstract}

CONCLUSION: Microemulsion and lipid-based emulsion propofol had similar inflammatory, biochemical and microscopy profiles. Thus, microemulsion propofol can be used as an alternative to lipid-based emulsion propofol.

Key words: Anesthetics. Intravenous. Propofol. Solvents. Inflammation. Microscopy. Rabitts. 


\section{Introduction}

Propofol is currently the agent of choice for both induction and maintenance of general anesthesia, but it is also used for sedation

during local anesthesia, in intensive care settings, and in mechanically ventilated patients to provide hypnotic and amnestic effects. Present commercial preparations are lipid-based emulsions containing $1 \%$ and $2 \%$ propofol formulated in $10 \%$ soybean oil.

Propofol as a lipid emulsion (LE) can cause allergic reactions, rapid bacterial growth due to the presence of organic products in its formulation, and burning sensations during injection $^{1-3}$. These adverse effects, inherent to LE, are likely to indicate aggression to the endothelium and limit its use. Thus, safer propofol formulations would be of great importance for clinical use $\mathrm{e}^{4,5}$.

Efforts have been made to reduce the adverse reactions to LE. Solutions with lower soy bean amounts, vehicles containing long- and medium-chain fatty acids, albumin emulsions, cyclodextrin formulations, aqueous solutions associated to phosphate radicals, among others, have all been tried. No such solutions significantly reduced propofol's adverse effects. However, some may have longer onset of action and recovery duration. A novel solvent, polyethylene glycol 660 hydroxystearate (Solutol $^{\circledR}$ HS15 - BASF, Ludwigshafen, Germany), which is a water-soluble nonionic solubilizer developed for use in lipophilic drugs and vitamins, has been used in microemulsions (ME). In association with propofol, this thermodynamically stable emulsifier can form microemulsions, with droplets of 10-50 nm, that seem not only to diminish the side effects and increase the shell life of the medication but also to decrease the amount of organic products in its formulation, and thus reduce the possibility of bacterial contamination. Furthermore, as it causes no pain when injected intravenously, it is probably less aggressive to the endothelium than the propofol solvent conventionally used.

The objective of this study was to compare the incidence of endothelial injury after single-dose or continuous propofol infusion in conventional lipid-based emulsion (LE) versus microemulsion (ME), and also to assess the inflammatory effects caused by both propofol formulations and their repercussions on hemodynamics, liver function, glycemia and electrolytes.

\section{Methods}

The protocol and procedures of this study were approved by the Committee of Use in Animal Care, Botucatu Medical School, Sao Paulo State University (UNESP).

Forty-two rabbits $(2.5-4.5 \mathrm{Kg})$ were randomly allocated into seven groups of six animals each. All animals received 25 $\mathrm{mg} / \mathrm{kg}$ of sodium pentobarbital to induce anesthesia followed by isoflurane in concentrations sufficient to maintain it.

\section{Experimental groups}

- $\quad$ SHAM Group (SHA) - six rabbits that did not receive any of the drugs under study;

- Bolus Control Group (BCG) - six rabbits that received a 3 mL-intravenous (IV) bolus of saline;

- Continous Infusion Control Group (CCG) - six rabbits that received saline as a $3 \mathrm{~mL}$ - IV bolus followed by a continuous infusion of $0.2 \mathrm{ml} / \mathrm{kg} / \mathrm{min}$ for 60 minutes;

- Bolus LE Propofol Group (BLP) - six rabbits that received an IV bolus of LE propofol (3 $\mathrm{mg} / \mathrm{kg})$;

- $\quad$ Bolus ME Propofol Group (BMP) - six rabbits that received an IV bolus of ME propofol (3 $\mathrm{mg} / \mathrm{kg})$;

- Continuous LE Propofol Group (CLP) - six rabbits that received LE propofol as an IV bolus ( $3 \mathrm{mg} / \mathrm{kg}$ ) followed by a continuous infusion of $0.2 \mathrm{ml} / \mathrm{kg} / \mathrm{min}$ for 60 minutes;

- Continuous ME Propofol Group (CMP) - six rabbits that received ME propofol as an IV bolus ( $3 \mathrm{mg} / \mathrm{kg}$ ) followed by a continuous infusion of $0.2 \mathrm{ml} / \mathrm{kg} / \mathrm{min}$ for 60 minutes.

\section{Measurements}

- Hemodynamic: mean arterial pressure $(\mathrm{mmHg})$ and central venous pressure $\left(\mathrm{cm} . \mathrm{H}_{2} \mathrm{O}\right)$

- Biochemical: plasma glycemia, plasma sodium, plasma potassium, AST- glutamic oxaloacetic transaminase, ALTglutamic-pyruvic transaminase, GGT - Gamma-glutamyl transpeptidase, ALP- alkaline phosphatase

- Inflammatory: Interleukin-6 (IL-6), Tumor necrosis factoralpha (TNF- alpha), Interferon gamma (IFN- gamma), Colony stimulating factor (CSF), and Endothelin.

- Tissue: Light and electron microscopy of the right jugular vein and right atrium.

\section{Study assessment time points and periods}

Hemodynamic parameters were recorded at the following time points:

- $\quad$ T0 -15 minutes after surgical preparation was ended;

- $\quad$ T1 - five minutes after bolus injection of propofol or saline in groups BCG, CCG, BLP, and BMP, or five minutes after continuous infusion in groups CLP and CMP; 
- $\quad$ T2 -15 minutes after bolus injection of propofol or saline in groups BCG, CCG, BLP, and BMP, or 15 minutes after continuous infusion in groups CLP and CMP;

- $\quad$ T3 - 60 minutes after bolus injection of propofol or saline in groups BCG, CCG, BLP, and BMP, or 60 minutes after continuous infusion in groups CLP and CMP - At this point in time, the animals were sacrificed by anesthetic overdose and the study was ended.

Blood was collected over the following periods:

- $\quad$ P0 - Blood collection for analysis of blood parameters in all groups at $\mathrm{T} 0$.

- $\quad$ P1 - Blood collection for analysis of blood parameters at 60 minutes after the study drug was injected in groups BCG, CCG, BLP and BMP, or 60 minutes after continuous infusion was started in CLP and CMP, which corresponded to the end of the experiment.

- Blood samples were collected into vacutainers, centrifuged, aliquoted into three cryovials, and stored at $-80^{\circ} \mathrm{C}$ until analysis.

- $\quad$ Tissue parameters were recorded at the end of the experiment.

- At the end of the experiment, (sacrifice), samples of the right side jugular vein and right atrium were collected for anatomopathological analyses (light and electron microscopy).

\section{Experimental sequence}

Mean arterial pressure (MAP) and central venous pressure (CVP) were measured using a transducer (Datex Angstron, model $\mathrm{AS} / 3$ ) connected to the right carotid artery and the left jugular vein.

Sections of the right jugular vein (RJV) and right atrium (RA) were analyzed under light and electron microscopy. By the end of the experiment, RJV samples were collected from the site where the catheter tip was inserted for infusion (proximal sample) and $3 \mathrm{~cm}$ downward (distal sample). Samples of the right atrium mid-portion were also collected.

\section{Light microscopy}

After immersion in 10\% formalin buffer solution for 24 hours, RJV and RA segments were carefully washed, immersed in $70 \%$ alcohol, stained with Hematoxylin-Eosin (HE), and mounted on slides. All slides were examined by a pathologist without prior knowledge of the experimental conditions.
Histological findings were graded from zero to three according to lesion severity $(0=$ none, $1=$ mild, $2=$ moderate, $3=$ severe $)$ and extension $(0=$ none, $1=$ up tp $1 / 3$ of the section, $2=$ up to $2 / 3$ of the section, $3=$ more than $2 / 3$ of the section).

The increase in size observed in the nuclei of endothelial cells was scored based on a 1-3 scale where $1=$ small, $2=$ moderate, and $3=$ large.

\section{Electron microscopy}

After primary fixation in 4\% paraformaldehyde and $2.5 \%$ glutaraldehyde in $0.1 \mathrm{M}$ phosphate buffer $(\mathrm{pH}=7.3)$ for 24 hours, RJV and RA segments were post-fixed in 1\% osmium in the same buffer for two hours, and incubated for $2 \mathrm{~h}$ in $0.5 \%$ aqueous uranyl acetate. The specimens were then dehydrated in a graded acetone series, and embedded in epoxy resin (Araldite $\square$ ). Sections of $0.5 \mu \mathrm{m}$ were stained in $1 \%$ methylene, mixed with $1 \%$ azur II and 1\% borax. Ultrathin sections, cut from selected blocks, were contrasted with uranyl acetate solution saturated in 50\% alcohol and lead citrate. Analysis was performed under a Philips, CM100, transmission electronic microscope, and documented with Eastman-5302 35-mm film (Kodak).

\section{Quantification of inflammatory mediators}

Circulating IL- 2, IL-4, IL-6, IL-8, IL-10, TNF, INF, CSF and endothelin were simultaneously quantified by flow cytometric immunoassay.

\section{Statistical analysis}

Statistical analyses were performed with the Statistical Package for the Social Sciences (SPSS) version 17.0, using Profile Analysis. Significance level was set at $\mathrm{p}<0.05$.

Profile analysis was used when variables were normally distributed and variances were homogeneous. Otherwise, the test of Friedman was used for intra-group comparisons and the Kruskal Wallis test for comparison among groups at different time points.

For variables analyzed only once, variance analysis for a random design was used when variable distribution was normal, and the Kruskal Wallis test was used when the distribution was not normal. As hemodynamic and biochemical variables were not normally distributed, non-parametric tests were used. The Kruskall-Wallis test was used for comparisons among groups, followed by the test of multiple comparisons, when applicable, and the test of Wilcoxon for comparisons among time points. 
As inflammatory variables were normally distributed, a profile analysis was performed.

Light microscopy findings were compared among groups by a non-parametric Kruskall-Wallis test, followed by a Dunn test for multiple comparisons.

\section{Results}

\section{Hemodynamic variables}

There were no statistical differences in MAP and CVP among the groups and time points studied.

\section{Biochemical variables}

There were no statistical differences in biochemical variables among the groups and time points studied.

\section{Inflammatory variables}

Of the interleukins studied, only IL-6 statistically differed among time points in groups SHA and CCG.

Endothelin concentration showed a time-dependent increase in all groups studied, irrespective of whether propofol in ME or LE, or saline infusion was used.

\section{Tissue variables}

Light microscopy of the RJV (Proximal and distal)

No statistical difference regarding the extension and intensity of nuclear hyperchromasia was observed among groups. However, in the groups receiving continuous infused propofol in ME or LE, there was a greater increase in mean cell nucleus size with no difference between solvents. As inflammation extension and severity was assessed, the group CLP showed a significant increase in relation to the group SHA, but did not differ from the other groups. In the group CMP, endothelial edema was larger than in groups SHA and BCG, but no statistical difference was found when it was compared with the group CLP. Subendothelial edema severity was greater in the group CMP than in the group SHA. No statistical difference was observed when comparison was made with the group CLP because all animals in the group CMP showed severe subendothelial edemas, while the animals in the group CLP displayed edemas that varied from moderate to severe (Tables 1 and 2; Figures 1 and 2)
TABLE 1 - Median, 1st and e 3rd quartile, between brackets, of variable scores for proximal and distal vessels according to group.

\begin{tabular}{cccccc}
\hline & \multicolumn{5}{c}{ Variable } \\
\cline { 2 - 6 } Group & $\begin{array}{c}\text { Nuclear } \\
\text { hyperchromasia } \\
\text { extension }\end{array}$ & $\begin{array}{c}\text { Nuclear } \\
\text { hyperchromasia } \\
\text { intensity }\end{array}$ & $\begin{array}{c}\text { Nuclear size } \\
\text { increase }\end{array}$ & $\begin{array}{c}\text { Extension of } \\
\text { inflammation }\end{array}$ & $\begin{array}{c}\text { Intensity of } \\
\text { inflammation }\end{array}$ \\
\hline SHA & $3.0[3.0 ; 3.0]$ & $3.0[3.0 ; 3.0]$ & $0.0[0.0 ; 0.0] \mathrm{C}$ & $0.0[0.0 ; 0.0] \mathrm{B}$ & $0.0[0.0 ; 0.0] \mathrm{C}$ \\
BLP & $3.0[3.0 ; 3.0]$ & $3.0[3.0 ; 3.0]$ & $1.0[1.0 ; 2.0] \mathrm{BC}$ & $1.0[1.0 ; 2.0] \mathrm{AB}$ & $2.0[1.0 ; 2.0] \mathrm{BC}$ \\
BCG & $3.0[2.0 ; 3.0]$ & $3.0[2.0 ; 3.0]$ & $1.0[1.0 ; 2.0] \mathrm{ABC}$ & $2.0[0.0 ; 2.0] \mathrm{AB}$ & $1.0[0.0 ; 1.0] \mathrm{ABC}$ \\
CCG & $3.0[3.0 ; 3.0]$ & $3.0[3.0 ; 3.0]$ & $2.0[0.0 ; 2.0] \mathrm{ABC}$ & $2.0[0.0 ; 3.0] \mathrm{AB}$ & $2.0[0.0 ; 3.0] \mathrm{ABC}$ \\
CMP & $3.0[2.0 ; 3.0]$ & $3.0[2.0 ; 3.0]$ & $2.0[2.0 ; 3.0] \mathrm{AB}$ & $2.0[2.0 ; 3.0] \mathrm{AB}$ & $2.0[2.0 ; 3.0] \mathrm{AB}$ \\
BMP & $2.0[2.0 ; 3.0]$ & $3.0[2.0 ; 3.0]$ & $2.0[1.0 ; 3.0] \mathrm{ABC}$ & $2.0[1.0 ; 2.0] \mathrm{AB}$ & $2.0[1.0 ; 3.0] \mathrm{ABC}$ \\
CLP & $3.0[2.0 ; 3.0]$ & $3.0[2.0 ; 3.0]$ & $3.0[2.0 ; 3.0] \mathrm{A}$ & $3.0[2.0 ; 3.0] \mathrm{A}$ & $3.0[3.0 ; 3.0] \mathrm{A}$ \\
\hline P value & 0.06 & 0.37 & $<0.001$ & $<0.001$ & $<0.001$ \\
\hline
\end{tabular}

Capital letters compare groups

Groups followed by at least one letter in common do not statistically differ

TABLE 2 - Median, 1st and e 3rd quartile, between brackets, of variable scores for proximal and distal vessels according to group.

\begin{tabular}{ccccc}
\hline & \multicolumn{4}{c}{ Variable } \\
\cline { 2 - 5 } Group & $\begin{array}{c}\text { Extension of } \\
\text { inflammation }\end{array}$ & $\begin{array}{c}\text { Intensity of } \\
\text { inflammation }\end{array}$ & $\begin{array}{c}\text { subendothelial } \\
\text { edema extension }\end{array}$ & $\begin{array}{c}\text { subendothelial edema } \\
\text { severity }\end{array}$ \\
\hline SHA & $0.0[0.0 ; 0.0]$ & $0.0[0.0 ; 0.0]$ & $0.0[0.0 ; 0.0] \mathrm{C}$ & $0.0[0.0 ; 0.0] \mathrm{B}$ \\
BLP & $0.0[0.0 ; 0.0]$ & $0.0[0.0 ; 0.0]$ & $2.0[1.0 ; 3.0] \mathrm{AB}$ & $2.0[2.0 ; 2.0] \mathrm{AB}$ \\
BCG & $0.0[0.0 ; 0.0]$ & $0.0[0.0 ; 0.0]$ & $0.0[0.0 ; 2.0] \mathrm{BC}$ & $0.0[0.0 ; 2.0] \mathrm{B}$ \\
CCG & $0.0[0.0 ; 0.0]$ & $0.0[0.0 ; 0.0]$ & $0.0[0.0 ; 2.0] \mathrm{ABC}$ & $1.0[0.0 ; 3.0] \mathrm{AB}$ \\
CMP & $0.0[0.0 ; 1.0]$ & $0.0[0.0 ; 1.0]$ & $3.0[2.0 ; 3.0] \mathrm{A}$ & $3.0[3.0 ; 3.0] \mathrm{A}$ \\
BMP & $0.0[0.0 ; 0.0]$ & $0.0[0.0 ; 0.0]$ & $2.0[2.0 ; 2.0] \mathrm{ABC}$ & $2.0[2.0 ; 3.0] \mathrm{AB}$ \\
CLP & $1.0[0.0 ; 2.0]$ & $1.0[0.0 ; 1.0]$ & $3.0[0.0 ; 3.0] \mathrm{AB}$ & $3.0[1.0 ; 3.0] \mathrm{AB}$ \\
\hline P value & 0.06 & 0.07 & $<0.001$ & $<0.001$ \\
\hline
\end{tabular}

Capital letters compare groups

Groups followed by at least one letter in common do not statistically differ 
Effects of propofol in lipid-based emulsion and in microemulsion on the incidence of endothelial lesion in rabbits

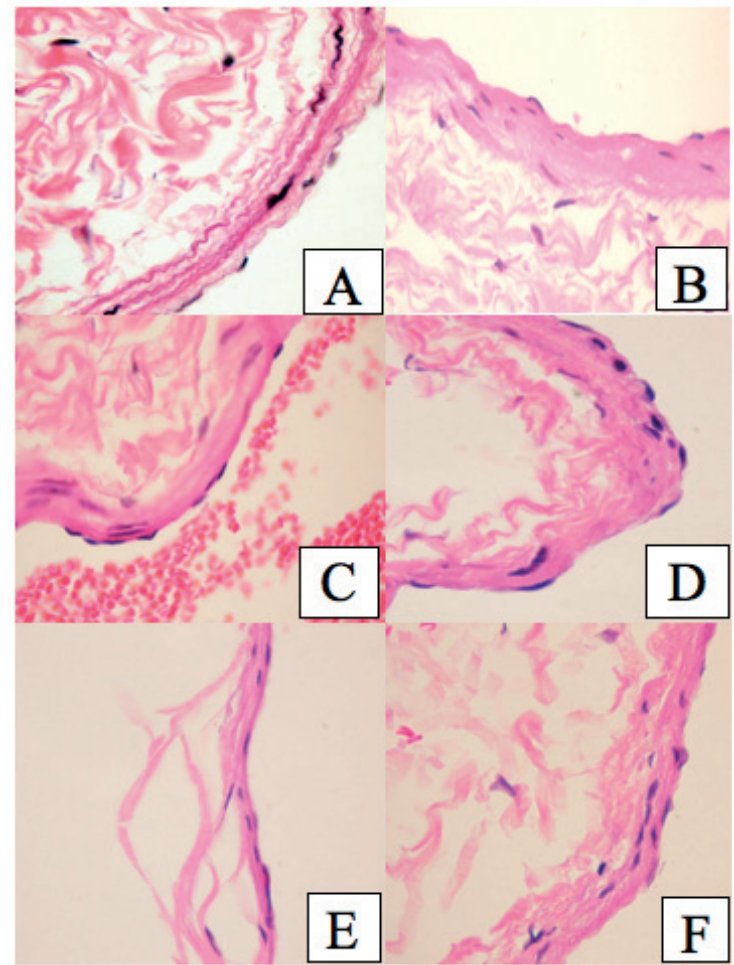

FIGURE 1 - A and B) BMP animal 30G: Nuclear hyperchromasia, high nuclei and subendothelial edema HE. x100; C and D) CLP animal 4H: Nuclear hyperchromasia and subendothelial edema HE. x100; E and F) CMP animal 13H: Nuclear hyperchromasia and subendothelial edema HE. x200 and x400; (notice that subendothelial edema intensity differs among groups).

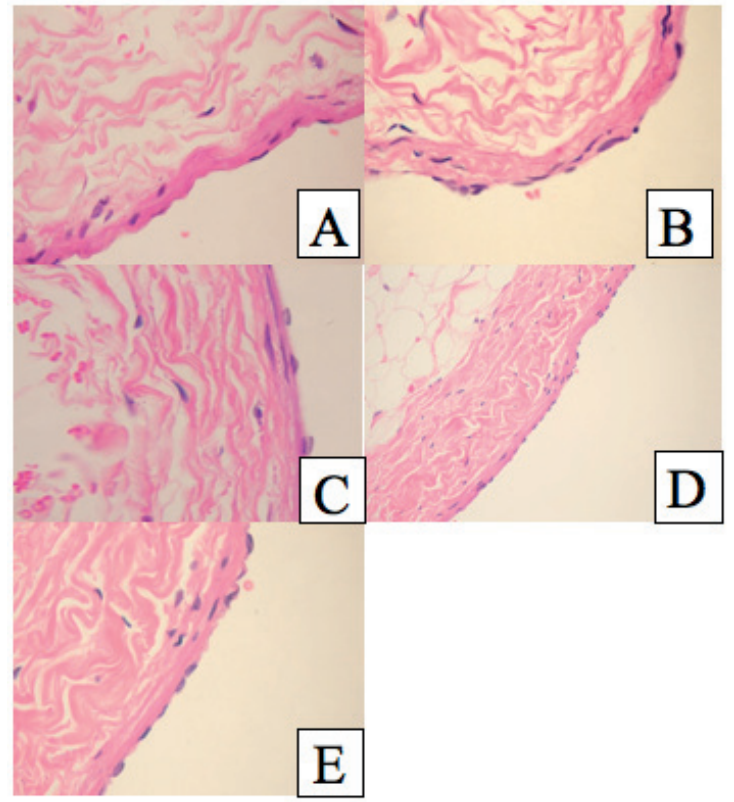

FIGURE 2 - A and B) Sha animal 3G: Usual aspect of the vessel wall and endothelium HE. x100 and x400; C and D) BCG animal 11H: presence of high nuclei and absence of subendothelial edema subendotelial $\times 400$ and x1000; E) CCG animal 22H: presence of high nuclei and discreet subendothelial edema HE x400.

\section{Right atrium}

There were no differences among the groups studied. The group BMP showed a tendency toward a larger number of damaged cells than the other groups, but statistical significance was not reached.

\section{Transmission electron microscopy (MET)}

Given that analyses were performed at very high magnification, MET results were focal and described slide by slide. Lymphocyte infiltrates were found in the endothelium of the vessels submitted to propofol infusion. Since the endothelium normally repels these cells, this finding is indicative of endothelial damage.

The major findings observed in the slides obtained from the groups studied were as follows (Figures 3 to 6 ).

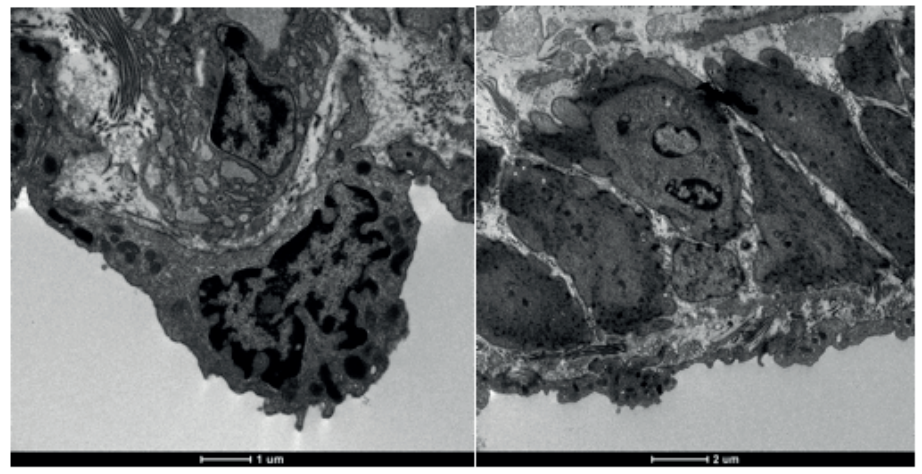

FIGURE 3 - Intact endothelial nucleus.

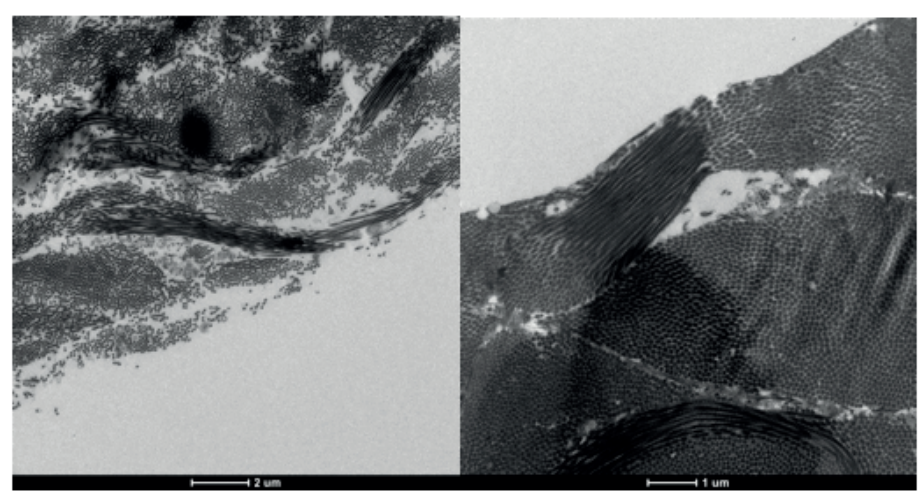

FIGURE 4 - Endothelial detachment and discreet collagen fiber rearrangement 


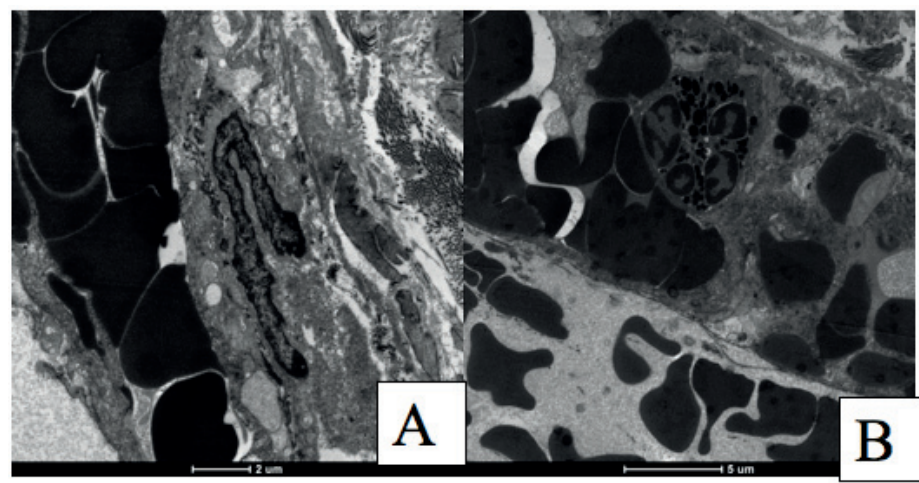

FIGURE 5 - A. Endothelial inflammatory process. B. Presence of white cell next to the endothelial cell nucleus.

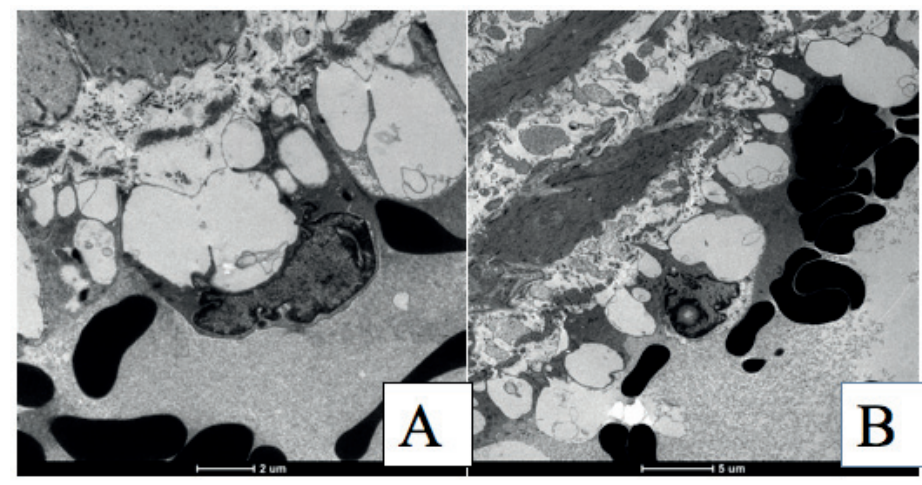

FIGURE 6 - A. Disarranged connective tissue. B. White cell invading the endothelium.

SHA No visible alterations.

BCG Intact endothelial nucleus and normal endothelial cell.

CCG Inflammatory process. Endothelial cell invaded by white cell.

BLP Discreet endothelial displacement.

CLP Endothelial detachment and discreet collagen fibers rearrangement.

BMP Presence of small bubbles within the nucleus.

CMP Slightly disorganized connective tissue. Inflammatory process with white cells around the nucleus. Disarranged cellular tissue.

\section{Discussion}

Under the experimental conditions of the present study, no significant statistical difference was observed among groups regarding the use of lipid-based emulsion or microemulsion solvents and saline.

Only tissue variables, as revealed by both light and TEM microscopy, indicated a tendency toward greater cell damage and subendothelial edema in the group receiving propofol in microemulsion.

\section{Hemodynamics}

Propofol is known to induce greater reduction in systolic arterial pressure than sodium thiopental ${ }^{6}$, as well as to produce $12 \%$ and $15 \%$ decreases in cardiac output and systemic vascular resistance, respectively ${ }^{7}$. Such lowering in vascular resistance has been attributed to sympathetic activity inhibition, while cardiac output reduction may be associated with decreased intracellular calcium availability resulting from reduced trans-sarcolemmal calcium influx ${ }^{8,9}$. In this study, no significant drop in mean arterial pressure was observed among the animals receiving propofol as compared with those receiving saline or no solution. This might be due to the fact that the animals were already anesthetized, which might have diminished the influence of the autonomous nervous system on the maintenance of systemic vascular resistance. Furthermore, the effects of propofol on arterial pressure are more intense in older, hypovolemic patients with impaired left ventricular function. The fact that the animals used in this study were healthy and pre-hydrated attenuated the hypotensive response to propofol.

No significant changes in mean arterial pressure or in central venous pressure were observed with any of the solvents tested, although ME has been reported to produce larger concentrations of free aqueous propofol than LE. In this study, this did not lead to greater decrease in mean arterial pressure ${ }^{5,10}$. This was also observed by Morey et al. ${ }^{11}$, who investigated the hemodynamic aspects of propofol in microemulsion in dogs. While comparing macroemulsions with microemulsions, they did not find significant variation in mean arterial pressure ${ }^{11}$. Sudo et al. ${ }^{5}$ also did not detect significant differences in mean arterial pressure when comparing propopofol in macroemulsion versus microemulsion in rats.

\section{Biochemistry}

Few electrolytic alterations have been associated with the use of propofol. When present, such alterations most frequently occur after prolonged infusions ${ }^{12}$. Part of the electrolytic alterations result from the use of antimicrobial agents such as EDTA, present in lipid emulsions. EDTA, in prolonged infusions, can briefly affect the homeostasis of plasma electrolytes such as calcium, magnesium, zinc, copper and cobalt ${ }^{13}$. However, this was not observed in this study. Neither the continuous infusion nor the bolus injection of the different emulsions caused any significant electrolyte variation. 
Regarding the enzymes AST, ALT, ALP and GGT, Kimura et al. ${ }^{14}$ reported increased AST concentration on post-operative day 1 in a study conducted with patients with ASA physical status I or II receiving anesthesia with propofol for elective operations. Such observation, however, might have been biased by the fact that the type and duration of the surgical procedure are related with postoperative enzyme alterations. Patients submitted to prolonged pneumoperitoneum very often show increased AST and ALT concentrations, irrespective of the type of anesthesia used ${ }^{15}$. Consistently with our results, other authors did not detect any significant change in the concentration of these enzymes during the study period ${ }^{16,17}$.

In line with other reports ${ }^{18}$, no significant change in glycemia was observed in the groups receiving propofol, whether in ME or LE, as compared with the SHAM and control groups.

\section{Inflammatory mediators}

Only some of the many existing cytokines were analyzed in this study. Among them, only IL-6, which is abundantly released by endothelial cells, is implicated in endothelial permeability ${ }^{19,20}$, and can regulate the acute immune response ${ }^{21}$, showed significant alterations among the groups studied.

Propofol has been demonstrated to have anti-inflammatory effects, especially in a state of inflammation overload, that reduce the biosyntheses of TNF- $\alpha$, IL-1 $\beta$, and IL-6 in vitro ${ }^{22}$. Moreover, propofol seems to attenuate neutrophil chemotactic function, phagocytosis, respiratory burst activity, and, specifically, IL-8 concentration $^{23}$. In this study, the use of propofol and its vehicles did not cause changes in IL-8 concentration. However, the maintenance of high IL-6 levels not allowing the clearance of this interleukin was observed in groups such as SHA and CCG. Crozier et al. ${ }^{24}$ also demonstrated increased IL- 6 concentration in patients receiving propofol. However, compared with isoflurane, propofol seemed to attenuate the increase in circulating IL-6. Comparison between ME and LE yielded no significant difference. Thus, it is possible to infer that the attenuation of IL-6 increase does not depend on the type of solvent used.

Endothelin concentration did not significantly differ with the type of propofol solvent used or between treated animals and controls. However, a time-dependent increase in endothelin concentration was observed in all groups. Endothelin-1 (ET1 ) is one of the most potent endogenous vasoconstrictor. It is released continuously from endothelial cells, smooth muscle cells, leukocytes, macrophages and neurons, and contributes to the maintenance of vascular tone. ET-1 release is strongly inhibited by nitric oxide (NO), as well as by conditions of reduced NO production that culminate in increased serum endothelin concentrations such as chronic renal failure, heart failure, diabetes, and others ${ }^{25}$. Propofol has been associated with reduction in endothelin concentration, especially following cerebral ischemia. However, inhalation anesthetics, such as isoflurane, can inhibit constitutive NO synthase ${ }^{26,27}$. Thus, as all groups in this study were maintained with isoflurane, a time-dependent increase in endothelin concentration was expected.

\section{Light microscopy}

Our light microscopy findings showed that the groups receiving propofol in microemulsion tended to show a larger number of damaged cells and subendothelial edema of greater severity. Propofol is recognized to affect neutrophil migration, but little is known about the effects of the solvent on endothelial lesion under light microscopy ${ }^{28}$. This study detected no change in inflammatory mediators that could explain the higher intensity of the subendothelial injury. It is possible that this higher intensity partially resulted from a localized endothelial lesion with focal increases in inflammatory mediators that were not sufficient elevated systemic concentrations. Furthermore, microemulsification seems to cause a lesion in addition to that provoked by propofol, especially when continuously infusion is used.

\section{Electron microscopy}

The behavior of electron microscopy findings was very similar to that of light microscopy. There was a tendency toward a more intense inflammatory response with the use of ME. However, even in the control group that only received saline, endothelial alterations with neutrophil infiltrates were observed.

In normal situations, the endothelium is known to repel these cells, which are only present in cases of endothelial lesion with acute inflammatory reaction.

In conclusion, animal studies might yield results different from those obtained in human studies. However, some animal species are better suited than humans for some investigations. This present study, which involved the examination of the endothelium and the right atrium, would only be possible using animals. Thus, the rabbit was chosen as the experiment animal for its proximity to humans regarding inflammatory response. Moreover, specific kits for measuring cytokines in this animal species are easily available. Thus, although not the ideal, the rabbit was the animal 
species closest to humans regarding the main topic of this study, which was the analysis of possible endothelial lesions caused by different propofol solvents from the standpoint of inflammatory variables.

\section{Conclusion}

Microemulsion and lipid-based emulsion propofol had similar inflammatory, biochemical and microscopy profiles. Thus, microemulsion propofol can be used as an alternative to lipidbased emulsion propofol.

\section{References}

1. Egan TD, Kern SE, Johnson KB, Pace NL. The pharmacokinetics and pharmacodynamics of propofol in a modified cyclodextrin formulation (Captisol) versus propofol in a lipid formulation (Diprivan): an electroencephalographic and hemodynamic study in a porcine model. Anesth Analg. 2003;97(1):72-9.

2. Song D, Hamza MA, White PF, Byerly SI, Jones SB, Macaluso AD. Comparison of a lower-lipid propofol emulsion with the standard emulsion for sedation during monitored anesthesia care. Anesthesiology. 2004;100(5):1072-5.

3. Rodrigues TA, Alexandrino RA, Kanczuk ME, Gozzani JL, Mathias LA. A comparative study of non-lipid nanoemulsion of propofol with solutol and propofol emulsion with lecithin. Rev Bras Anestesiol. 2012;62(3):325-34.

4. Baker MT, Naguib M. Propofol: the challenges of formulation. Anesthesiology. 2005;103(4):860-76.

5. Sudo, RT, Bonfá L, Trachez MM, Debom R, Rizzi MD, ZapataSudo G. Anesthetic profile of a non-lipid propofol nanoemulsion. Rev Bras Anestesiol. 2010;60(5):475-83.

6. Rouby JJ, Andreev A, Léger P, Arthaud M, Landault C, Vicaut E, Maistre G, Eurin J, Gandjbakch I, Viars P. Peripheral vascular effects of thiopental and propofol in humans with artificial hearts. Anesthesiology. 1991;75(1):32-42.

7. Coates DP, Monk CR, Prys-Roberts C, Turtle M. Hemodynamic effects of infusions of the emulsion formulation of propofol during nitrous oxide anesthesia in humans. Anesth Analg. 1987;66(1):6470 .

8. Robinson BJ, Ebert TJ, O'Brien TJ, Colinco MD, Muzi M. Mechanisms whereby propofol mediates peripheral vasodilation in humans. Sympathoinhibition or direct vascular relaxation? Anesthesiology. 1997;86(1):64-72.

9. Warpechowski P, dos Santos AT, Pereira PJ, de Lima GG. Effects of propofol on the cardiac conduction system. Rev Bras Anestesiol. 2010;60(4):438-44.

10. Lee EH, Lee SH, Park DY, Ki KH, Lee EK, Lee DH, Noh GJ. Physicochemical properties, pharmacokinetics, and pharmacodynamics of a reformulated microemulsion propofol in rats. Anesthesiology. 2008;109(3):436-47.

11. Morey TE, Modell JH, Shekhawat D, Grand T, Shah DO, Gravenstein N, McGorray SP, Dennis DM. Anesthetic properties of a propofol microemulsion in dogs. Anesth Analg. 2006;103(4):882-7.

12. Gronert GA, Haskins SC, Steffey EP, Fung D. Plasma electrolyte and metabolite concentrations associated with pentobarbital or pentobarbital-propofol anesthesia during three weeks' mechanical ventilation and intensive care in dogs. Lab Anim Sci.1998;48(5):513-
9.

13. Cohen IT, Hannallah RS, Goodale DB. The clinical and biochemical effects of propofol infusion with and without EDTA for maintenance anesthesia in healthy children undergoing ambulatory surgery. Anesth Analg. 2001;93(1):106-11.

14. Kimura T, Hasegawa M. Effect of intra-operative propofol administration on post-operative serum lipid concentrations. Masui. 2001;50(9):1009-11.

15. Morino M, Giraudo G, Festa V. Alterations in hepatic function during laparoscopic surgery. An experimental clinical study. Surg Endosc. 1998;12(7):968-72.

16. Martin PH, Murthy BV, Petros AJ. Metabolic, biochemical and haemodynamic effects of infusion of propofol for long-term sedation of children undergoing intensive care. Br J Anaesth. 1997;79(3):2769 .

17. Ozlü O, Ozkara HA, Eris S, Ocal T. Propofol anaesthesia and metabolic acidosis in children. Paediatr Anaesth. 2003;13(1):53-7.

18. Kitamura T, Ogawa M, Kawamura G, Sato K, Yamada Y. The effects of sevoflurane and propofol on glucose metabolism under aerobic conditions in fed rats. Anesth Analg. 2009;109(5):1479-85.

19. Ali MH, Schlidt SA, Chandel NS, Hynes KL, Schumacker PT, Gewertz BL. Endothelial permeability and IL-6 production during hypoxia: role of ROS in signal transduction. Am J Physiol. 1999;277(5 Pt 1):L1057-65.

20. Romano M, Sironi M, Toniatti C, Polentarutti N, Fruscella P, Ghezzi P, Faggioni R, Luini W, van Hinsbergh V, Sozzani S, Bussolino F, Poli V, Ciliberto G, Mantovani A. Role of IL-6 and its soluble receptor in induction of chemokines and leukocyte recruitment. Immunity. 1997;6(3):315-25.

21. Akdis M, Burgler S, Crameri R, Eiwegger T, Fujita H, Gomez E, Klunker S, Meyer N, O'Mahony L, Palomares O, Rhyner C, Ouaked N, Schaffartzik A, Van De Veen W, Zeller S, Zimmermann $\mathrm{M}$, Akdis CA. Interleukins, from 1 to 37, and interferon-gamma: receptors, functions, and roles in diseases. J Allergy Clin Immunol. 2011;127(3):701-21 e1-70.

22. Chen RM, Chen TG, Chen TL, Lin LL, Chang CC, Chang HC, $\mathrm{Wu} \mathrm{CH}$. Anti-inflammatory and antioxidative effects of propofol on lipopolysaccharide-activated macrophages. Ann N Y Acad Sci. 2005; 1042:262-71.

23. Galley HF, Dubbels AM, Webster NR. The effect of midazolam and propofol on interleukin-8 from human polymorphonuclear leukocytes. Anesth Analg. 1998;86(6):1289-93.

24. Crozier TA, Müller JE, Quittkat D, Sydow M, Wuttke W, Kettler D. Effect of anaesthesia on the cytokine responses to abdominal surgery. Br J Anaesth. 1994;72(3):280-5.

25. Thorin E, Webb DJ. Endothelium-derived endothelin-1. Pflugers Arch. 2010;459(6):951-8.

26. Wei X, Wan X, Zhao B, Hou J, Liu M, Cheng B. Propofol inhibits inflammation and lipid peroxidation following cerebral ischemia/ reperfusion in rabbits. Neural Regen Res. 2012;7(11):837-41.

27. Zuo Z, Tichotsky A, Johnsb RA. Halothane and isoflurane inhibit vasodilation due to constitutive but not inducible nitric oxide synthase. Implications for the site of anesthetic inhibition of the nitric oxide/guanylyl cyclase signaling pathway. Anesthesiology. 1996;84(5):1156-65.

28. Hofbauer R, Frass M, Salfinger H, Moser D, Hornykewycz S, Gmeiner B, Kapiotis S. Propofol reduces the migration of human leukocytes through endothelial cell monolayers. Crit Care Med. 1999;27(9):1843-7. 
Correspondence:

Luiz Antonio Vane

Faculdade de Medicina de Botucatu-UNESP

Departamento de Anestesiologia

Caixa postal 530

18618-970 Botucatu - São Paulo Brasil

Tel.: (55 14)3880-1414

lavane@uol.com.br

Received: Aug 14, 2013

Review: Oct 10, 2013

Accepted: Nov 12, 2013

Conflict of interest: Cristália ${ }^{\circledR}$ Produtos Químicos e Farmacêuticos

Financial source: Sao Paulo Research Foundation (FAPESP)

${ }^{1}$ Research performed at Experimental Laboratory of Anesthesiology,

Botucatu Medical School, Sao Paulo State University (UNESP),

Botucatu-SP, Brazil. Part of Master degree thesis, Postgraduate Program in Anesthesiology. Tutor: Luiz Antonio Vane. 